\title{
How to Make Phoenix to Arise from the Ashes: Brand Loyalty as a Prospective Pillar of Branding in Tourism after Crisis COVID-19
}

\author{
Jana Majerova1 ${ }^{1}$, Carlos Fernandes² \\ ${ }^{1}$ University of Zilina, Slovak Republic \\ ${ }^{2}$ Polytechnic Institute of Viana do Castelo, Portugal
}

\begin{abstract}
Current global situation has radically examined the applicability of many managerial patterns which have been created so far. The reason is that crisis COVID-19 has changed not only established frameworks of managerial practice but also functional frameworks of consumer behaviour. There is no guaranty of occurring forecasted scenarios of market development. Black swan has flown also over the brands which have been traditionally perceived as valuable. So, the aim of this paper is to discuss brand loyalty as a prospective pillar of brand value resuscitation in tourism and to identify relevant brand value sources significant to brands characterised by loyalty. On the case study of Slovak consumer perception of brand value sources, it is possible to verify so far formulated postulates and modified theories, which take into account relevance of national psychographic specifics. Primary data used in the presented study were obtained by our own survey carried out on the sample of 2,000 respondents. The given data were statistically evaluated by the factor analysis supported by implementation of KMO Test, Barlett's test of sphericity and calculation of Cronbach's Alpha for relevant brand loyalty sources in tourism. By providing this statistical evaluation of the results, it has been possible to identify relevant brand value sources which are suitable to modify methodological apparatus of brand value building and management.
\end{abstract}

Keywords: brand, brand management, branding, brand value, brand loyalty 


\section{Introduction}

Traditional econometric models of marketing analysis are dominated primarily by 1) Platonic approach to argumentation and 2) abstracting from extreme values as immanent components of surveyed statistical files and phenomena. Platonic approach to argumentation consists in focussing on explicitly defined contents and ideas of their functional mechanisms. This naturally tends to favour of existing intellectual maps and thinking constructs at the expense of pro-innovative, creative and unconventional solutions conforming to market dynamics. Abstracting from extreme values makes it impossible to explore phenomena in their entirety, and concentrates only to the extent that corresponds to Gaussian normal distribution of values. However, for the sake of a true understanding of market reality, it is necessary to realize that it is the extreme values and cases that play a key role in the context of taking competent managerial decisions. The COVID-19 pandemic has caused a $22 \%$ fall in international tourist arrivals during the first quarter of 2020, the latest data from the World Tourism Organization (UNWTO) shows. According to the United Nations specialized agency, the crisis could lead to an annual decline of between $60 \%$ and $80 \%$ when compared with 2019 . Thus, also in tourism and hospitality any ex-post descriptive analyses as well as ex-ante predictive analyses and constructed models have given rise to discussions on their applicability in the context of the current challenges of marketing management. Among them, the phenomenon of the black swan is dominant, which confronts hitherto created concepts of marketing management with the reality of uncertainty in economic environment. This creates space for building a relevant theoretical basis for optimizing of the decision-making processes of brand managers.

\section{Literature Review}

Brand loyalty is traditionally considered as one of the key aspects of effective brand value building and management across products and markets. Fernandes and Moreira (2019) analysed differences in consumer brand engagement according to the functional or emotional nature of consumer-brand relationships and its direct and/or indirect impact on brand loyalty. Khamitov et al. (2019) found out that while elasticities are generally highest for love-based and attachment-based brand relationships, the positive influence of brand relationships on customer brand loyalty is stronger in more recent (vs. earlier) years, for nonstatus (vs. status) and publicly (vs. privately) consumed brands, and for estimates using attitudinal (vs. behavioral) customer brand loyalty. Drawing on relational tie theory and theory of trust, Ozdemir et al. (2020) examine the role of affective and cognitive trust in mediating the relationship between corporate brands and consumers, and in loyalty towards corporate brands of national dairy products in China. They find out that while cognitive trust mediates the relationships between certain corporate brand and consumer constructs, including corporate brand competence and corporate brand communication and loyalty, affective trust mediates the effect of loyalty on corporate brand and consumer relationship constructs, including corporate brand communication, 
corporate brand liking and corporate brand similarity. According to Huang et al. (2020), brand image is indirectly correlated with both repurchase and advocacy intention through cognitive brand trust, and brand image is indirectly related to advocacy intention through affective brand trust. Cuong et al. (2020) use social exchange theory and the principle of reciprocity in proposing a theoretical model to examine the essential but unexplored unique roles of individual customer equity drivers and their contribution to brand loyalty. Their study identifies a reciprocity pathway in that brand equity, which mediates the linkage between relationship equity and brand loyalty. However, brand loyalty is not analysed in details in scope of tourism and hospitality. Its importance is only stated on the positive basis of experience form other industries. Few brand loyalty specified on tourism mostly discuss location branding. Liu et al. (2020) examine to what extent emotional place attachment is impacted by people's feelings towards international companies associated with the place, and what mechanism and conditions drive such effects. They highlight that tourism marketers need to appropriately manage perceptions of local brands' authenticity and consider cultural distance when designing destination campaigns in their efforts to strengthen place attachment. This is the reason why Mody et al. (2017) conclude that while many research focused on brand loyalty has been conducted at the destination level, tourists' loyalty towards their intermediary has not been considered. Nowadays, this fact is partially invalidated by Taylor et al. (2020) who pay attention to the specific interaction between brand loyalty in case of places, tour operators and hospitality services providers. Another trend in modern tourism branding research is the phenomenon of sharing economy. Mody and Hanks (2020) state that hotels and Airbnb draw upon different sources of authenticity to create brand-loving customers. Their results indicated that Airbnb leverages brand, existential, and intrapersonal authenticity in creating brand-loving and brand-loyal customers, while hotels utilize only brand authenticity. Thus, the keys to creating customers who love and are loyal to the brand differ between hotels and Airbnb. Implications for theory and practice are discussed, and areas of future research are identified. As a rapidly evolving global pandemic, COVID-19 provides several opportunities for tourism researchers to study the resilience of the tourism industry from a socioecological system perspective (Prayag, 2020). COVID-19 is widely recognised as a challenge or even a game-changer for travel and tourism (Higgins-Desbiolles, 2020). Sigala (2020) on the contrary discusses why and how the COVID-19 can be a transformational opportunity by discussing the circumstances and the questions raised by the pandemic. Shao et al. (2020) provide insights into further research on health-related crises and crisis recovery management in tourism, especially for developing countries and regions by identifying four core themes of interest, namely (i) prophylactic measures, (ii) tourism recovery and development, (iii) policy support, and (iv) departmental management. Assaf and Scuderi (2020) develop their theory and analyse separately brand loyalty as relevant aspect of managing brand value in contemporary post-COVID-19 time. However, detailed analysis of brand value sources significant for brands characterized by loyalty presence is missing. 


\section{Methods and Data}

According to the literature review above, the main aim of the article is to identify brand value sources of loyalty which are relevant to brand value building management in tourism. To achieve this aim, we have used the data from our own research provided on the socio-demographically representative sample of 2,000 respondents during the first half of 2020. This research has been conducted via a questionnaire survey in the form of computer-assisted web interviewing respecting the ICC/ESOMAR International code on Market, Opinion and Social Research and Data Analytics. The questionnaire was administered in Slovak Republic among its inhabitants over 15 years of age. Thus, the main presumption of autonomous buying decision-making has been fulfilled because this age is considered as a basic presumption for legal working subjectivity. The questionnaire consisted of three parts with the following reasoning:

- the first part covered the general socio-demographic profile of respondents;

- the second part covered questions about perception of brand value sources generally, and

- the third part covered questions about perception of brand value sources in details across the traditional typology of buying behavior and representative product categories.

Brand value sources are analyzed in their traditional structure defined by Aaker - that is, (1) imageries; (2) attitudes; (3) attributes, and (4) benefits. The components of brand value sources are set in accordance with provided literature review and with relevance to so far identified specifics of psychographic profile of Slovak consumers (See Table 1).

Tab. 1: Coding of brand value sources and their components relevant to further research evaluation

\begin{tabular}{|l|l|r|}
\hline \multicolumn{1}{|c|}{$\begin{array}{c}\text { Brand Value } \\
\text { Sources }\end{array}$} & \multicolumn{1}{c|}{ Components of Brand Value Sources } & Code \\
\hline imageries & happiness & 4 \\
\hline & expectations & 5 \\
\hline & satisfaction & 1 \\
\hline & certainty & 2 \\
\hline & positive associations & 3 \\
\hline & I aim to buy branded products & 13 \\
\hline & I am interested in branded products on a regular basis & 12 \\
\hline & branded products attract my attention because I consider them better & 11 \\
\hline & branded products attract my attention because I consider them more & 14 \\
\hline & prestigious & 19 \\
\hline & quality & 16 \\
\hline & creativity of ad & 15 \\
\hline & popularity & 17 \\
\hline & availability & 18 \\
\hline & innovativeness & 10 \\
\hline & branded product makes me happier & 8 \\
\hline & branded product increases my social status & 6 \\
\hline & branded product makes it easier for me to get friends & 7 \\
\hline & branded product attracts the attention of others & 9 \\
\hline & branded product belongs to my lifestyle & 14 \\
\hline
\end{tabular}

Source: Authors. 
Factor analysis has been chosen as the main statistical tool for evaluation of the consumer's perception of brand value sources in case of brand loyalty in tourism. This analysis is one of the groups of multidimensional statistical methods which are used to create so-called factors (previously unobservable variables) to reduce the amount of originally set attributes without losing the relevant information obtained inside the data set. Recently, this statistical tool has been used with higher frequency in the social sciences due to the boom in information technology development and the need of reducing subjectivity. The definition of the relevant statistical model as well as the identification of rational assumptions is the base of this analysis. In the process of identification of relevant factors, it is primarily important to identify and test the dependence between originally defined variables through the correlation matrix. The basic presumption for the data reduction is the correlation of these variables verified by the correlation matrix creation as well as the fulfilment of the assumption that identified correlation exists as a consequence of less undetected hidden variables (factors). Based on this, it is possible to diversify originally defined variables into partial groups. In these groups, there are unified factors which internally correlate more inside the group than in comparison with other groups.

We assume that $\mathrm{x}$ is a $\mathrm{p}$-dimensional random vector of the considered variables with $\mathrm{a}$ vector of mean values $\mu$, a covariance matrix $C(X)=\Sigma$, and a correlation matrix of simple correlation coefficients $\mathrm{P}(\mathrm{X})=\mathrm{P}$. One of the basic assumptions of factor analysis is the existence of $\mathrm{R}$ common background factors $F_{1}, F_{2}, \ldots, F_{R}$; trying to have them as little as possible, preferably less than $\mathrm{p}$. The P-dimensional random vector consists of the $j$ observable random variables $x_{j}, j=1,2, \ldots, p$; which can be expressed by Equation (1) as

$$
X_{j}=\mu_{j}+\gamma_{j 1} F_{1}+\gamma_{j 2} F_{2}+\ldots+\gamma_{j R} F_{R}+\varepsilon_{j}
$$

where $\varepsilon_{1}, \varepsilon_{2}, \ldots, \varepsilon_{p}$ are p stochastic error terms referred to as specific factors. If we write this in matrix, we get the Equation (2):

$$
x=\mu+\Gamma f+\varepsilon,
$$

where $\Gamma$ is a matrix of factors loadings type $\mathrm{p} \mathrm{R}$; $f$ is R-member vector of common factors, and $\varepsilon$ is p-member vector of specific factors. Factors loadings can be considered as regression coefficients $\mathrm{p}$ of observed variables on $\mathrm{R}$ nonobservable factors, and when certain conditions of solution are met, they are also covariance between the original and the new variables. Factors loadings can be interpreted as the contribution of the r-factor of the j-specified variable, when the same units of measurement are used. To determine the adequacy of the statistical sample, we use the KMO (Kaiser-Meyer-Olkin) Test Equation (3):

$$
K M O=\frac{\sum_{j \neq j^{\prime}}^{p} \sum_{j \neq j^{\prime}}^{p} r^{2}\left(x_{j}, x_{j^{\prime}}\right)}{\sum_{j \neq j^{\prime}}^{p} \sum_{j \neq j^{\prime}}^{p} r^{2}\left(x_{j}, x_{j^{\prime}}\right)+\sum_{j \neq j^{\prime}}^{p} \sum_{j \neq j^{\prime}}^{p} r^{2}\left(x_{j}, x_{j^{\prime}} \text { other } x\right)}
$$

where $r^{2}\left(x_{j}, x_{j^{\prime}}\right)$ are simple correlation coefficients and $r^{2}\left(x_{j}, x_{j^{\prime}} \cdot\right.$ other $\left.x\right)$ are partial correlation coefficients under the condition of statically constant remaining $\mathrm{p}-2$ variables. $\left(x_{1}, x_{2}, \ldots, x_{j}-1, x_{j+1}, \ldots, x_{j^{\prime}}-1, x_{j^{\prime}}+1, x_{p}\right)$. 
Required value of KMO test should be higher than 0.6. By acquiring it, the adequacy of statistical sample is proved. Required value of Barlett's test of sphericity should be lower than 0.05. By acquiring it, the dependence between variables is proved. Required value of Cronbach's Alpha should be higher than 0.8. By acquiring it, the intrinsic consistency of the factors is proved. Detection of the optimal values of these tests forms appropriate basis to the identification of the order of brand value sources.

\section{Results}

The KMO (Kaiser-Meyer-Olkin) test has indicated the adequacy of the statistical sample used $(>0.6)$. When testing the brand value sources in tourism, a value of 0.931 has been acquired. Bartlett's test of sphericity has proved the existence of dependence between variables by acquiring a resulting value of $0.00(<0.05)$. The testimonial value of factor analysis in the case of research on sources of brand value in general has reached a value of $74.617 \%$ (Table 2).

Tab. 2: Total variance explained

\begin{tabular}{|c|c|c|c|c|c|c|c|c|c|}
\hline \multirow{2}{*}{$\begin{array}{l}+ \\
\stackrel{+}{0} \\
0\end{array}$} & \multicolumn{3}{|c|}{ Initial Eigenvalues } & \multicolumn{3}{|c|}{$\begin{array}{c}\text { Extraction Sums of Squared } \\
\text { Loadings }\end{array}$} & \multicolumn{3}{|c|}{$\begin{array}{c}\text { Rotation Sums of Squared } \\
\text { Loadings }\end{array}$} \\
\hline & Total & \begin{tabular}{|c|}
$\%$ of \\
Variance
\end{tabular} & $\begin{array}{c}\text { Cumulative } \\
\%\end{array}$ & Total & \begin{tabular}{|c|}
$\%$ of \\
Variance
\end{tabular} & $\begin{array}{c}\text { Cumulative } \\
\%\end{array}$ & Total & \begin{tabular}{c|}
$\%$ of \\
Variance
\end{tabular} & $\begin{array}{c}\text { Cumulative } \\
\%\end{array}$ \\
\hline 1 & 9.500 & 50.002 & 50.002 & 9.500 & 50.002 & 50.002 & 4.177 & 21.982 & 21.982 \\
\hline 2 & 2.080 & 10.949 & 60.951 & 2.080 & 10.949 & 60.951 & 3.941 & 20.741 & 42.723 \\
\hline 3 & 1.456 & 7.665 & 68.616 & 1.456 & 7.665 & 68.616 & 3.125 & 16.446 & 59.170 \\
\hline 4 & 1.140 & 6.001 & 74.617 & 1.140 & 6.001 & 74.617 & 2.935 & 15.448 & 74.617 \\
\hline 5 & 0.685 & 3.606 & 78.223 & & & & & & \\
\hline 6 & 0.480 & 2.527 & 80.751 & & & & & & \\
\hline 7 & 0.425 & 2.235 & 82.986 & & & & & & \\
\hline 8 & 0.413 & 2.171 & 85.157 & & & & & & \\
\hline 9 & 0.392 & 2.061 & 87.218 & & & & & & \\
\hline 10 & 0.359 & 1.889 & 89.106 & & & & & & \\
\hline 11 & 0.309 & 1.625 & 90.732 & & & & & & \\
\hline 12 & 0.294 & 1.547 & 92.279 & & & & & & \\
\hline 13 & 0.280 & 1.473 & 93.752 & & & & & & \\
\hline 14 & 0.261 & 1.372 & 95.124 & & & & & & \\
\hline 15 & 0.247 & 1.301 & 96.426 & & & & & & \\
\hline 16 & 0.222 & 1.169 & 97.595 & & & & & & \\
\hline 17 & 0.171 & 0.899 & 98.494 & & & & & & \\
\hline 18 & 0.151 & 0.797 & 99.291 & & & & & & \\
\hline 19 & 0.135 & 0.709 & 100.000 & & & & & & \\
\hline
\end{tabular}

Source: Authors.

In the case of brand value sources which are significant for brand loyalty in tourism, the existence of four relevant factors with significant components has been proven. These factors are: 1) imageries with five components where the value of Cronbach's Alpha was 0.854 ; 2) benefits with five components where the value of Cronbach's Alpha was 0.837; 3) attitudes with four components where the value of Cronbach's Alpha value was 0.841 and 4) attributes with five components where the value of Cronbach's Alpha was 0.869 (Table 3). 
Tab. 3: Rotated component matrix

\begin{tabular}{|c|c|c|c|c|}
\hline \multirow{2}{*}{ Code 4} & \multicolumn{4}{|c|}{ Brand value source } \\
\hline & Imageries & Benefits & Attitudes & Attributes \\
\hline 1 & 0.800 & & & \\
\hline 2 & 0.781 & & & \\
\hline 3 & 0.776 & & & \\
\hline 4 & 0.767 & & & \\
\hline 5 & 0.751 & & & \\
\hline 6 & & 0.880 & & \\
\hline 7 & & 0.860 & & \\
\hline 8 & & 0.850 & & \\
\hline 9 & & 0.604 & & \\
\hline 10 & 0.521 & 0.531 & & \\
\hline 11 & & & 0.812 & \\
\hline 12 & & & 0.784 & \\
\hline 13 & & & 0.762 & \\
\hline 14 & & 0.437 & 0.643 & \\
\hline 15 & & & & 0.784 \\
\hline 16 & & & & 0.752 \\
\hline 17 & & & & 0.747 \\
\hline 18 & & & & 0.586 \\
\hline 19 & 0.417 & & 0.411 & 0.559 \\
\hline
\end{tabular}

Source: Authors' own research in SPSS.

It has been also detected that, in the case of some components, their incorporation into factors is variant, more specifically in the case of: 1) branded products make me happier (imageries vs. benefits); 2) branded products attract my attention because I consider them more prestigious (benefits vs. attitudes) and 3) quality (imageries vs. attitudes vs. attributes).

\section{Discussion}

The imageries have been identified as the main brand value source relevant to loyalty creation and establishment in tourism. It means that components as happiness, expectations, satisfaction, certainty and positive associations are for consumers more important than quality (included simultaneously as component in various brand value sources) resp. social status (included in benefits). This finding is even more important in scope of COVID-19 crisis times due to the fact that "certainty" is connected with consumer expectations focused on health security and public safety. Similarly, as it is stated by Khamitov et al. (2019) and Ozdemir et al. (2020), brand loyalty is a relevant driver of brand success if it is created on appropriate brand value sources. It has been also developed the concept of Taylor et al. (2020) where integrated view on tourism has been applied without taking into consideration internal variability of tourism research. However, it would be useful to apply for comparative reasons also this wider point of view as COVID-19 crisis has specific impact on 1) place branding vs. 2) branding of tourism and hospitality services providers. It is mainly because of the trend stated by Mody and Hanks (2020) who have found out that the keys to creating customers who love and are loyal to the brand differ between hotels and Airbnb. Contemporary global situation indicates the 
change of preferences in tourism in favour of the sharing economy concepts. The reason are the concerns about the COVID-19 pandemic on public places. This assumption can be considered as one of the most important challenges which have been highlighted by Prayag (2020) and Higgins-Desbiolles (2020). On the contrary, Sigala (2020) perceive COVID-19 as a transformational opportunity. In accordance with this approach, it can be concluded that systematic exploitation of brand loyalty benefits in brand value building and management in tourism and systematic revision of so far formulated branding patterns, is relevant response to the opportunity created by COVID-19 pandemic. However, research outcomes have some significant limitations of general applicability. They lie in the fact that the recommendations which have been done on the basis of research outcomes are valid only in scope of Slovak consumer's preferences. Thus, possible implementations of statements which result from research itself are applicable only in case of tourism services focused on Slovak consumers (domestic or foreign).

\section{Conclusion}

The aim of the paper was to constructively discuss brand loyalty as a prospective pillar of brand value resuscitation in tourism. On the case study of Slovak consumer perception of brand value sources, it has been possible to identify relevant brand value sources significant to brands characterised by loyalty. Methodologically, primary data used in the presented study were obtained by our own survey carried out on the sample of 2,000 respondents. The given data were statistically evaluated by the factor analysis supported by implementation of relevant statistical tests. It has been found out that these brand value sources are: 1) imageries; 2) benefits; 3) attitudes and 4) attributes. Thus, it has been created a valuable source of relevant information with anticipation to enhance and deepen the understanding of previous practice as well as to provide relevant content to consumers, responding to rapidly changing consumer demands and expectations in times of black swan appearance.

\section{Acknowledgement}

This contribution is a partial output of scientific project APVV-15-0505: Integrated model of management support for building and managing the brand value in the specific conditions of the Slovak Republic.

\section{References}

ASSAF, A. and R. SCUDERI, 2020. COVID-19 and the recovery of the tourism industry. Tourism Economics, 26(5), p. 731-733. doi: 10.1177/1354816620933712.

CUONG, P.H. et al., 2020. Not all experiential consumers are created equals: The interplay of customer equity drivers on brand loyalty. European Journal of Marketing, 54(9), p. 2257-2286. doi: 10.1108/EJM-04-2018-0228. 
FERNANDES, T. and M. MOREIRA, 2019. Consumer brand engagement, satisfaction and brand loyalty: A comparative study between functional and emotional brand relationships. Journal of Product and Brand Management, 28(2), p. 274-286. doi: 10.1108/JPBM-08-2017-1545.

HIGGINS-DESBIOLLES, F., 2020. The "war over tourism": challenges to sustainable tourism in the tourism academy after COVID-19. Journal of Sustainable Tourism, 29(4), p. 551-569. doi: 10.1080/09669582.2020.1803334.

HUANG, L. et al., 2020. Brand image and customer loyalty: Transmitting roles of cognitive and affective brand trust. Social Behavior and Personality, 48(5), e9069. doi: 10.2224 /sbp.9069.

KHAMITOV, M., X. WANG and M. THOMSON, 2019. How well do consumer-brand relationships drive customer brand loyalty? Generalizations from a meta-analysis of brand relationship elasticities. Journal of Consumer Research, 46(3), p. 435-459. doi: $10.1093 /$ jcr/ucz006.

LIU, Y.Y. et al., 2020. How does brand loyalty interact with tourism destination? Exploring the effect of brand loyalty on place attachment. Annals of Tourism Research, 81, UNSP 102879. doi: 10.1016/j.annals.2020.102879.

MODY, M. and L. HANKS, 2020. Consumption authenticity in the accommodations industry: The keys to brand love and brand loyalty for hotels and Airbnb. Journal of Travel Research, 59(1), p. 173-189. DOI: 10.1177/0047287519826233.

MODY, M. et al., 2017. Integrating country and brand images: Using the product-Country image framework to understand travelers' loyalty towards responsible tourism operators. Tourism Management Perspectives, 24, p. 139-150. doi: 10.1016/j.tmp.2017.08.001.

OZDEMIR, S. et al., 2020. The effects of trust and peer influence on corporate brandConsumer relationships and consumer loyalty. Journal of Business Research, 117, p. 791805. doi: 10.1016/j.jbusres.2020.02.027.

PRAYAG, G., 2020. Time for reset? COVID-19 and tourism resilience. Tourism Review International, 24(2-3), p. 179-184. doi: 10.3727/154427220X15926147793595.

SHAO, Y.H. et al., 2020. What is the policy focus for tourism recovery after the outbreak of COVID-19? A co-word analysis. Current Issues in Tourism, early access: AUG 2020. doi: 10.1080/13683500.2020.1806798.

SIGALA, M., 2020. Tourism and COVID-19: Impacts and implications for advancing and resetting industry and research. Journal of Business Research, 117, p. 312-321. doi: 10.1016/j.jbusres.2020.06.015.

TAYLOR, S. et al., 2020. Will travel for beer: An assessment of beer-focused and non-beer focused tourists' perceived similarity, brand loyalty and place loyalty. Journal of Destination Marketing \& Management, 15, 100405. doi: 10.1016/j.jdmm.2019.100405. 
DOI: https://doi.org/10.36708/Littera_Scripta2020/2/5

\section{Contact address of the authors:}

doc. JUDr. Ing. Jana Majerova, PhD., Department of Economics, Faculty of Operation and Economics of Transport and Communications, University of Zilina, Univerzitna 1, 01026 Zilina, Slovak Republic, e-mail: jana.majerova@fpedas.uniza.sk

Carlos Fernandes, Ph.D., Scholar \& Researcher in Tourism and Gastronomy, Polytechnic Institute of Viana do Castelo, Avenida do Atlântico, n.. 644, 4900-348 Viana do Castelo, Portugal, e-mail: cfernandes@estg.ipvc.pt 